\title{
Comparative determination of miconazole, nystatin, hydrocortisone and neomycin by HPTLC/HPLC-DAD
}

\author{
Ismail Salama * and Mohamed Sayed Gomaa \\ Department of Pharmaceutical Chemistry, Faculty of Pharmacy, Suez Canal University, Ismailia 41552, Egypt \\ *Corresponding author at: Department of Pharmaceutical Chemistry, Faculty of Pharmacy, Suez Canal University, Ismailia 41552, Egypt. \\ Tel.: +20.012.80327695; fax: +20.064.3230741. E-mail address: ismail mohamed@daad-alumni.de (I. Salama).
}

\section{ARTICLE INFORMATION}

Received: 28 December 2012

Received in revised form: 20 January 2013

Online: 31 March 2013

\section{KEYWORDS}

HPTLC

Nystatin

Neomycin

HPLC-DAD

Miconazole nitrate

Hydrocortisone acetate
Accepted: 20 January 2013

\begin{abstract}
Two new validated methods for the quantification of miconazole (MIC), nystatin (NYS), hydrocortisone acetate (HCA) and neomycin (NS) by high performance thin layer chromatography (HPTLC)-densitometry and reverse-phase high-performance liquid chromatography procedure coupled with photodiode array detector (RP-HPLC-DAD) were developed and compared. HPTLC separations were performed using a mobile phase, ethylacetate:methanol:glacial acetic acid (60:40:0.4, v:v:v) for MIC, NYS, HCA and ethylacetate for NS. For HPLC-DAD analysis, using an isocratic elution system, separation of all compounds was achieved. Good resolution and quantization were achieved, accuracy and precision, as well as detection and quantitation limits of the two methods, were evaluated and compared. Excellent linearity was observed for all of the standard calibration curves, and the correlation coefficients were above 0.9997 . HPTLC limits of quantitation were $15.37 \times 10^{-2}, 9.8 \times 10^{-2}$ $13.32 \times 10^{-2}$ and $15.19 \times 10^{-2} \mu \mathrm{g} / \mathrm{mL}$ for MIC, NYS, HCA and NS respectively, whereas HPLC limits were $6.80 \times 10^{-2}, 6.56 \times 10^{-2}, 1 \times 10^{-1}$ and $10.16 \times 10^{-2} \mu \mathrm{g} /$ band for MIC, NYS, HCA and NS respectively. In comparison with HPLC, HPTLC is less expensive and faster procedure, requiring 2-3 h to analyse 10-12 samples on a single plate. The developed methods were proved to be specific, robust and accurate for the determination of cited drugs in pharmaceutical preparations.
\end{abstract}

\section{Introduction}

Miconazole nitrate (MIC) [l- $(2,4$-dichloro- $\beta-((2,4-$ chlorobenzyl)oxy)phenethyl)imidazole], a synthetic imidazole derivative, is applied widely as the nitrate salt with a broadspectrum antifungal activity [1,2]. It is established as a useful drug for the treatment of various systemic mycoses. It is also active against Gram-positive bacteria. Nystatin (NYS) is a polyene antifungal antibiotic that is of particular interest because it exhibits remarkable action against a wide range of pathogenic and non-pathogenic yeast and fungi $[3,4]$.

Hydrocortisone acetate (HCA) is a human glucocorticosteroid which is often combined with nystatin and oxytetracycline [5] in different pharmaceutical preparations.

Neomycin (NS) is a water-soluble complex of aminoglycosides produced from the fermentation of the actinomycete Streptomyces fradiae [6-9]. Neomycin is used to treat bacterial infections in animals because of their good spectrum of activity against gram-negative bacteria.

Several analytical methods in the literature describing the determination of miconazole nitrate [10-14] or nystatin [1519] alone or in combination with other drugs have been reported. We have previously developed in our laboratory HPLC and chemometric methods for the simultaneous determination of MIC and NYS in their pharmaceutical formulations [20].

In the literature, various spectrophotometric methods for the determination of hydrocortisone [21,22] alone and with lidocaine [23], were reported. Other methods include determination of hydrocortisone in pharmaceuticals by TLC
[24] and HPLC [25-27] and in biological fluids [28-30] using HPLC with different methods of detection.

For neomycin a high-performance liquid chromatography (HPLC)-fluorescence after post column derivatization of serum [31], TLC after derivatization with fluram of plasma [32] or HPLC-tandem-MS [33] and a HILIC-tandem-MS method [34] was described. Neomycin lacks an usable chromophore however, derivatization of its primary amino groups is possible [35].

From the above-cited literature, no analytical method has been reported for the simultaneous analysis of NS with primary amine containing drugs other than aminoglycosides using UV detection. The main advantage of the developed method is to separate and analyze NS without interference from other drugs, in the mixture, with its derivatization procedure. Furthermore, the main objectives of this work were to develop, validate and compare two new HPLC-DAD and HPTLC methods for the simultaneous determination of NYS, MIC, HCA and NS in pharmaceutical preparations.

\section{Experimental}

\subsection{Materials and reagents}

Miconazole nitrate, Nystatin and Neomycin sulphate were kindly supplied by medical union pharmaceuticals (MUP), Ismailia City, Egypt and certified to contain 99.8, 99.9 and from Egyptian International pharmaceutical industries company (EIPICO). 99.9\%, respectively. Hydrocortisone acetate (98.75\%) was 
Commercial Monicure $\mathrm{NH} \circledast$ vaginal suppositories (Batch no. 7361109) (Pharaonia Pharmaceuticals, Alexandria City, Egypt) were used. Each vaginal suppository was labeled to contain $100 \mathrm{mg}$ (MIC), $100.000 \mathrm{IU}=20.5 \mathrm{mg}$ (NYS), $50 \mathrm{mg}$ (NS) and $5 \mathrm{mg}$ (HCA). Phenylisocyanate (PIC) and triethylamine (TEA) were purchased from Sigma. HPLC grade methanol (TEDIA, USA).Distilled water for HPLC was obtained following distillation in glass and passage through a Milli- $Q \circledR$ system (Millipore, Milford, MA, USA), filtered through $0.45 \mu \mathrm{m}$ membrane filter (Merck, Germany), degassed for 30 minutes in an ultrasonic bath. All other chemicals and reagents used were of analytical grade unless indicated otherwise.

\subsection{HPLC instrumentation and conditions}

HPLC analysis was carried out using a Hitachi LaChrom Elite liquid chromatograph L-2000 series equipped with photodiode array detector model L-2455, Hitachi La Chrom Elite (Tokyo, Japan), an Autosampler model L-2200, Hitachi LaChrom Elite (Tokyo, Japan), column oven model L-2300 Hitachi LaChrom Elite (Tokyo, Japan) and degasser built in model L-2130 pump.The column $(250 \mathrm{~mm} \times 4.6 \mathrm{~mm}$ i.d. $)$ was made of stainless steel and packed with Inertsil ODS-3v $(5 \mu \mathrm{m}$ particle diameter, GL Sciences, Tokyo, Japan). Data acquisition was performed on EZChrom Elite software (Agilent Technologies).

For MIC, NYS and HCA; the RP-HPLC- DAD assay was carried out using an isocratic elution system with a flow rate of $1 \mathrm{~mL} \mathrm{~min}^{-1}$. The mobile phase consisted of acetonitrile: $25 \mathrm{mM}$ $\mathrm{KH}_{2} \mathrm{PO}_{4}$ buffer $(\mathrm{pH}=2.8)$ in a ratio of 50:50 (v:v). For NS-PIC; The mobile phase consisted of acetonitrile: $25 \mathrm{mM} \mathrm{KH}_{2} \mathrm{PO}_{4}$ buffer $(\mathrm{pH}=2.8)(70: 30, v: v)$. The DAD acquisition wavelength was set to scan from 200 to $400 \mathrm{~nm}$, and all analyses were performed at ambient temperature $\left(25{ }^{\circ} \mathrm{C}\right)$. Before use, the mobile phase was filtered through $0.45 \mu \mathrm{m}$ membrane filters (Millipore, Milford, MA, USA) and degassed under vacuum.

\subsection{High-performance thin-layer chromatography and instrumentation}

HPTLC analysis were performed by using the computerized Camag HPTLC system (Camag, Muttenz, Switzerland) consisting in an automatic delivery system (TLC Linomat IV) and in a UV densitometer (TLC Scanner II). Data were stored andprocessed by appropriate software (Cats 3 via RS232 interface). Separation was achieved on HPTLC precoated silica gel $60 \mathrm{~F}$ plates, $10 \times 10 \mathrm{~cm}$ (Merck) using ethylacetate: methanol:glacial acetic acid $(60: 40: 0.4, v: v: v)$ as mobile phase for MIC, NYS and HCA while ethylacetate was used for NS-PIC. Samples were band applied (3 mm length) with a space of 4 $\mathrm{mm}$ under the nitrogen stream. Standard solutions of MIC, NYS, HCA and NS-PIC were applied to the same plates in incremental concentrations to obtain the calibration curves for each compound.

Chromatograms, developed in a saturated horizontal chamber, $10 \times 10 \mathrm{~cm}$ (Camag Muttenz, Switzer land), were evaluated via peak height after scanning in absorbancereflectance mode at $230 \mathrm{~nm}$ (MIC, NYS and HCA) and 240 (NSPIC). Keeping slit width at $3 \mathrm{~mm}$, slit length at $4 \mathrm{~mm}$ and scanning speed at $4 \mathrm{~mm} / \mathrm{s}$.

\subsection{Preparation of standard solutions and calibrations}

\subsubsection{For HPLC method}

Stock standard solutions of MIC, NYS and HCA $1 \mathrm{mg} / \mathrm{mL}$ were prepared in methanol. While for NS $1 \mathrm{mg} / \mathrm{mL}$ was prepared in water. The prepared solutions were stored at $4{ }^{\circ} \mathrm{C}$. The standard solutions were prepared by further dilutions of the stock standard solutions with mobile phase to reach the concentration ranges of $1-50 \mu \mathrm{g} / \mathrm{mL}$ for MIC, $2-100 \mu \mathrm{g} / \mathrm{mL}$ for
NYS, $1-35 \mu \mathrm{g} / \mathrm{mL}$ for HCA and $5-50 \mu \mathrm{g} / \mathrm{mL}$ for NS. Triplicate 20 $\mu \mathrm{L}$ injections were made for each concentration and chromatographed under the specified conditions. The peak area values versus corresponding concentrations were plotted. Linear relationships were obtained.

\subsubsection{For HPTLC method}

Stock standard solutions of the four drugs were prepared as for HPLC method. The standard solutions were prepared by further dilutions of the stock standard solutions with mobile phase to reach the concentration ranges of 3-60 $\mu \mathrm{g} / \mathrm{band}$ for MIC, $10-70 \mu \mathrm{g} / \mathrm{band}$ for NYS, 7-45 $\mu \mathrm{g} / \mathrm{band}$ for HCA and 5-100 $\mu \mathrm{g} / \mathrm{band}$ for NS. $5 \mu \mathrm{L}$ of each standard solution were applied to the HPTLC plates. Triplicate applications were made for each solution. The plates were developed using previously described mobile phases. The calibration curves were constructed relating the integrated area under the peak to the corresponding concentrations as $\mu \mathrm{g} / \mathrm{band}$.

\subsection{Preparation of Neomycin-PIC derivative}

For each concentration of the standard NS solutions in the linearity range, a $250 \mu \mathrm{L}$ aliquot of each standard solution was added to $250 \mu \mathrm{L}$ of phenylisocyanate solution $(5 \mathrm{mg} / \mathrm{mL}$ in acetonitrile) and $250 \mu \mathrm{L}$ of triethylamine solution $(5 \mathrm{mg} / \mathrm{mL}$ in acetonitrile). The mixture was reacted at room temperature and the resulting solution was shaken for several times.

\subsection{Sample preparation}

Five Monicure NH vaginal suppositories were accurately weighed and finely powdered in a mortar. An amount of the suppository mass equivalent to one suppository content (100 $\mathrm{mg}$ of MIC, $20.5 \mathrm{mg}$ of NYS. $50 \mathrm{mg}$ of NS and $5 \mathrm{mg}$ of HCA) was dissolved in $60 \mathrm{~mL}$ of water. After $30 \mathrm{~min}$ of warming and mechanical shaking, the solution was filtered in a $100 \mathrm{~mL}$ volumetric flask. The residue was washed twice, each with 10 $\mathrm{mL}$ of water. The volume was then completed to $100 \mathrm{~mL}$ with water. The residue was dissolved in methanol and the same procedure was followed. Further dilutions of the filtrates were conducted with mobile phase to reach the calibration range.

\section{Results and discussion}

We report here the separation and quantification of MIC, NYS, HCA, NS-PIC by both HPLC-DAD and HPTLC, and the analytical performance of the two methods was compared for their sensitivity, precision and linearity. NS is a weakly absorbing drug as it lacks a suitable pharmacophore and its quantification depends on the derivatisation of the drug with a suitable reagent to form a highly absorbing component that could be detected by HPLC/UV and HPTLC. However, one of the main problems of this concept is the interference from other amine containing drugs when present in mixture. This method depends on the separation of NS from MIC, NYS, HCA through differential solubility as the drug is water soluble while other components in the mixture are not. This is followed by derivatising the drug using phenyisocyanate as previously described in the literature [35]. Other components in the mixture are then easily determined as they all absorb well in the UV region. Other amine derivatising reagents as aldehydes and benzene sulphonyl chlorides were tried and phenylisocyanate gave the most accurate and reproducible results.

\subsection{Optimization of the HPLC-DAD method}

For separation of MIC, NYS and HCA; the mobile phase composition and $\mathrm{pH}$ of $25 \mathrm{mM} \mathrm{KH}_{2} \mathrm{PO}_{4}$ were studied and optimized. A successful separation was obtained with a mobile 
phase consisting of acetonitrile and $25 \mathrm{mM} \mathrm{KH}_{2} \mathrm{PO}_{4}$ buffer $(\mathrm{pH}$ $=2.8)$ in a ratio of $50: 50(\mathrm{v}: \mathrm{v})$ at a flow rate of $1 \mathrm{~mL} / \mathrm{min}$. First by trying $60 \% \mathrm{MeOH}: 30 \%$ Acetonitrile : $10 \% \mathrm{KH}_{2} \mathrm{PO}_{4}, \mathrm{pH}=6$, we found that the NYS peak was splitted and MIC eluted too late. Using $65 \% \mathrm{MeOH}$ : $35 \% \mathrm{KH}_{2} \mathrm{PO}_{4}, \mathrm{pH}=3.1$, NYS eluted at 24 min. An eluting system consisting of $60 \% \mathrm{MeOH}$ : 30\% acetonitrile: $10 \% \mathrm{NH}_{4}$ acetate, $\mathrm{pH}=6$, led to inadequate separation of HCA and NYS i.e eluted at the same retention time (3.6 min.). By decreasing acetonitrile:methanol ratio or using only methanol as organic modifier, we failed to separate NYS from HCA peaks with excessive tailing for the MIC peak.

However, using only acetonitrile and $\mathrm{KH}_{2} \mathrm{PO}_{4}$ at apparent $\mathrm{pH}=2.8$, optimum resolution with reasonable retention time was observed. For NS-PIC; a mobile phase, consisting of acetonitrile and $25 \mathrm{mM} \mathrm{KH}_{2} \mathrm{PO}_{4}$ buffer $(\mathrm{pH}=2.8)$ in a ratio of $70: 30(\mathrm{v}: \mathrm{v})$, was used at a flow rate of $1.5 \mathrm{~mL} / \mathrm{min}$.

These conditions gave optimum resolution, clear baseline separation with reasonable retention time and no tailing of peaks of the studied compounds (Figure 1).

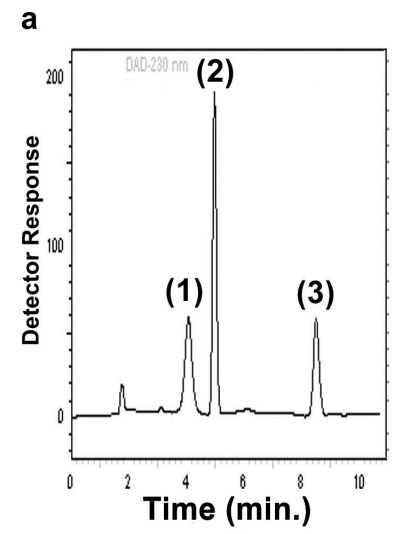

b

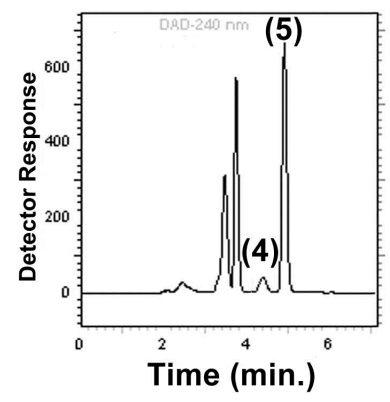

Figure 1. (a) HPLC chromatogram (20 mL injection volume) of laboratoryprepared mixture of (1) NYS, (2) HCA and (3) MIC; (b) reaction mixture (4) NSC-PIC and (5) NSB-PIC.

The three-dimensional UV absorption spectra of the studied compounds (Figure 2) show that $230 \mathrm{~nm}$ is the wavelength of maximum absorbance for MIC, NYS and HCA (Panel a). For NS-PIC, the wavelength of maximum absorbance was $240 \mathrm{~nm}$ (Panel b).

The specificity of the HPLC-DAD method is illustrated in Figure 1, in which complete separation of the three drugs (Figure 1a) and complete separation of Neomycin B-PIC(NSBPIC) (major) and Neomycin C-PIC (NSC-PIC) (minor) (Figure 1b) was observed.

\subsection{Optimization of the HPTLC Method}

Experimental conditions such as mobile phase and wavelength of scanning were optimized to provide accurate, precise and reproducible results for the simultaneous determination of the four analytes. The wavelength of scanning was chosen to be $230 \mathrm{~nm}$ for NYS, MIC and HCA while for NSPIC, it was $240 \mathrm{~nm}$. The greatest difference between the $\mathrm{R}_{\mathrm{f}}$ values of NYS, MIC and HCA with minimum tailing of NYS were obtained by using ethyl acetate:methanol:glacial acetic acid (60:40:0.4, v:v:v) while for NS-PIC; using glacial acetic acid cause disappearance of its spot under UV light which may be attributed to the hydrolysis of the derivatised drug. NS-PIC was eluted using only ethyl acetate. HPTLC densitograms for MIC, NYS and HCA are shown in the upper panel of Figure 3 and that for NSB-PIC and NSC-PIC are shown in the lower panel.

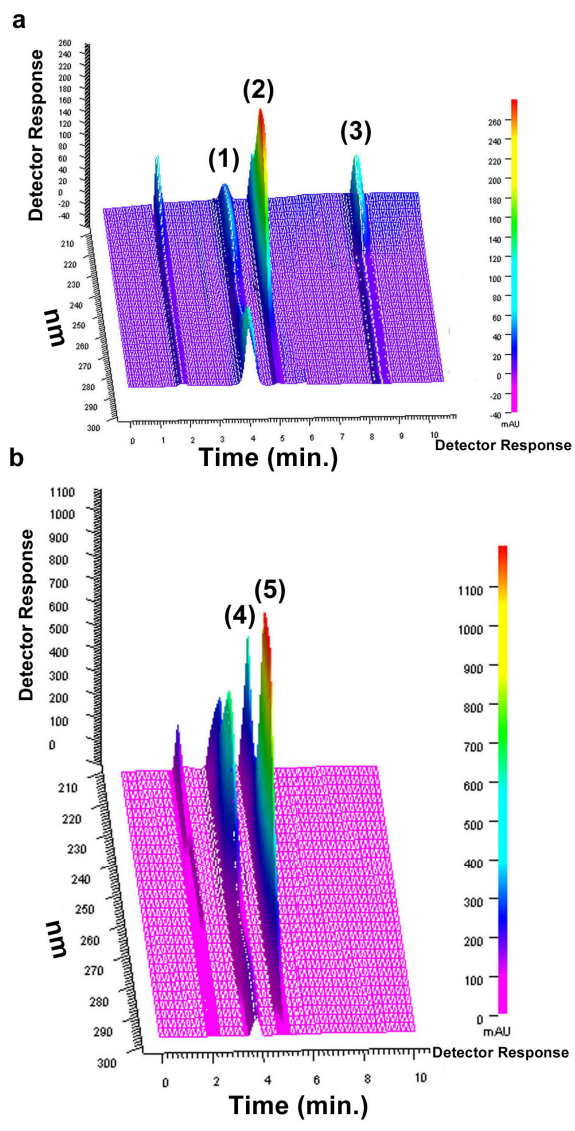

Figure 2. HPLC-DAD three-dimensional spectra of (a) laboratory-prepared mixture of (1) NYS, (2) HCA and (3) MIC; [b] reaction mixture (4) NSC-PIC and (5) NSB-PIC.

\subsection{Validation of the methods}

\subsubsection{Linearity}

The linearity of the HPLC and HPTLC methods for determination of MIC, NYS, HCA and NS were evaluated by analyzing a series of different concentrations of each drug. In this study, six concentrations were chosen, ranging between 1$50,2-100,1-35,5-50 \mu \mathrm{g} / \mathrm{mL}$ for MIC, NYS, HCA and NS respectively using HPLC method and 3-60, 5-70, 7-45 and 5$100 \mu \mathrm{g} / \mathrm{band}$ for MIC, NYS, HCA and NS respectively using HPTLC method. Each concentration was repeated three times, to provide information on the variation in peak area values between samples of the same concentration. The linearity of the calibration graphs was validated by the high value of the correlation coefficient and the intercept value, which was not statistically ( $p=0.05)$ different from zero. Characteristic parameters for regression equations of the HPLC and HPTLC methods obtained by least-squares treatment of the results are given in Table 1 and 2 . 
Table 1. Calibration curve data for MIC, NYS, HCA and NS using HPLC method.

\begin{tabular}{|c|c|c|c|c|}
\hline Regression parameters & MIC & NYS & HCA & NS \\
\hline Regression coefficient $(r)^{\text {a }}$ & 0.9999 & 0.9999 & 0.9998 & 0.9998 \\
\hline Calibration range $(\mu \mathrm{g} / \mathrm{mL})$ & $1-50$ & $2-100$ & $1-35$ & $5-50$ \\
\hline Detection limit (LOD) $(\mu \mathrm{g} / \mathrm{mL})$ & $2.00 \times 10^{-2}$ & $19.68 \times 10^{-3}$ & $3 \times 10^{-2}$ & $30.47 \times 10^{-3}$ \\
\hline Quantitation limit (LOQ) $(\mu \mathrm{g} / \mathrm{mL})$ & $6.80 \times 10^{-2}$ & $6.56 \times 10^{-2}$ & $1 \times 10^{-1}$ & $10.16 \times 10^{-2}$ \\
\hline Slope & $37.39 \times 10^{3}$ & $2.13 \times 10^{3}$ & $3.42 \times 10^{5}$ & $1.94 \times 10^{3}$ \\
\hline Standard deviation of slope & $3.27 \times 10^{2}$ & $0.17 \times 10^{2}$ & $4.38 \times 10^{3}$ & $0.25 \times 10^{2}$ \\
\hline Confidence limit of the slope ${ }^{b}$ & $37.07 \times 10^{3}-37.71 \times 10^{3}$ & $2.11 \times 10^{3}-2.15 \times 10^{3}$ & $3.37 \times 10^{5}-3.46 \times 10^{5}$ & $1.92 \times 10^{3}-1.97 \times 10^{3}$ \\
\hline Intercept & $-5.54 \times 10^{3}$ & $-0.19 \times 10^{2}$ & $0.09 \times 10^{5}$ & $-0.87 \times 10^{2}$ \\
\hline Standard deviation of the intercept & $9.19 \times 10^{3}$ & $7.85 \times 10^{2}$ & $1.23 \times 10^{5}$ & $6.41 \times 10^{2}$ \\
\hline Confidence limit of the intercept b & $-14.46 \times 10^{3}-3.39 \times 10^{3}$ & $-7.82 \times 10^{2}-7.44 \times 10^{2}$ & $-1.09 \times 10^{5}-1.29 \times 10^{5}$ & $-7.10 \times 10^{2}-5.36 \times 10^{2}$ \\
\hline
\end{tabular}

a The degree of freedom $=5$.

b Confidence limit $=95 \%$.

Table 2. Calibration curve data for MIC, NYS, HCA and NS using HPTLC method

\begin{tabular}{|c|c|c|c|c|}
\hline Regression parameters & MIC & NYS & HCA & NS \\
\hline Regression coefficient $(r)^{\text {a }}$ & 0.9997 & 0.9999 & 0.9997 & 0.9997 \\
\hline Calibration range ( $\mu \mathrm{g} / \mathrm{band})$ & $3-60$ & $5-70$ & $7-45$ & $5-100$ \\
\hline Detection limit (LOD) $(\mu \mathrm{g} / \mathrm{mL})$ & $46.12 \times 10^{-3}$ & $3 \times 10^{-2}$ & $39.98 \times 10^{-3}$ & $45.59 \times 10^{-3}$ \\
\hline Quantitation limit (LOQ) $(\mu \mathrm{g} / \mathrm{mL})$ & $15.37 \times 10^{-2}$ & $9.8 \times 10^{-2}$ & $13.32 \times 10^{-2}$ & $15.19 \times 10^{-2}$ \\
\hline Slope & $1.01 \times 10^{3}$ & $23.29 \times 10^{3}$ & $1.59 \times 10^{3}$ & $1.00 \times 10^{3}$ \\
\hline Standard deviation of slope & $0.19 \times 10^{2}$ & $2.93 \times 10^{2}$ & $0.27 \times 10^{2}$ & $0.19 \times 10^{2}$ \\
\hline Confidence limit of the slope ${ }^{b}$ & $0.98 \times 10^{3}-1.03 \times 10^{3}$ & $23.00 \times 10^{3}-23.57 \times 10^{3}$ & $1.56 \times 10^{3}-1.61 \times 10^{3}$ & $0.98 \times 10^{3}-1.02 \times 10^{3}$ \\
\hline Intercept & $-1.09 \times 10^{2}$ & $-12.59 \times 10^{3}$ & $3.39 \times 10^{2}$ & $-1.83 \times 10^{2}$ \\
\hline Standard deviation of the intercept & $7.60 \times 10^{2}$ & $14.31 \times 10^{3}$ & $4.74 \times 10^{2}$ & $7.48 \times 10^{2}$ \\
\hline Confidence limit of the intercept $\mathrm{b}$ & $-8.48 \times 10^{2}-6.28 \times 10^{2}$ & $-26.49 \times 10^{3}-1.31 \times 10^{3}$ & $-1.21 \times 10^{2}-8.00 \times 10^{2}$ & $-9.09 \times 10^{2}-5.44 \times 10^{2}$ \\
\hline
\end{tabular}

a The degree of freedom $=5$.

b Confidence limit $=95 \%$

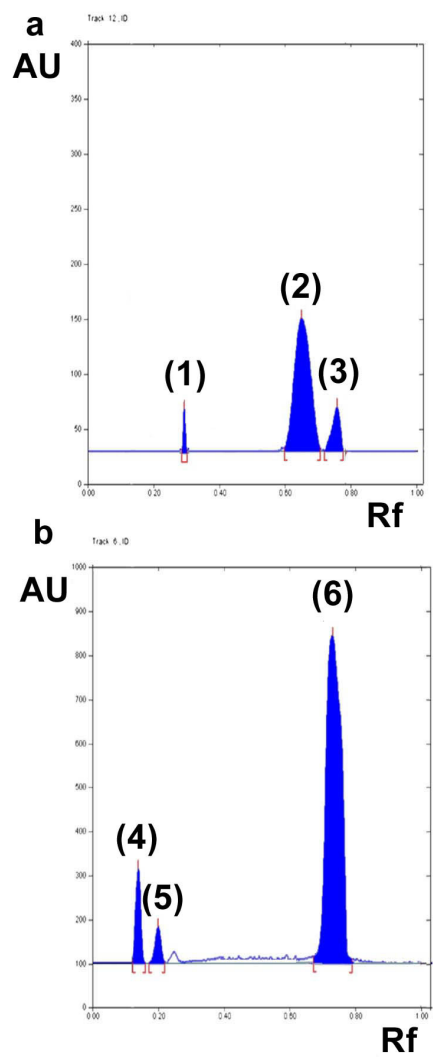

Figure 3. (a) HPTLC chromatogram of laboratory-prepared mixture of (1) NYS, (2) MIC and (3) HCA; (b) reaction mixture (4) NSB-PIC, (5) NSC-PIC and (6) PIC.

\subsubsection{Limits of detection (LOD) and quantification (LOQ)}

The limit of detection (LOD) and limit of quantification (LOQ) were calculated according to the current ICH guidelines as the ratio of 3.3 and 10 standard deviations of the blank ( $\mathrm{n}=$ 7) respectively, against the slope of the calibration line [36]. The LOD and LOQ are given in Table 1 and 2.

\subsubsection{Precision}

The intra-day and inter-day variations of the two methods were determined using three replicate injections of three different concentrations, which were prepared and analysed on the same day and on three different days over a period of two weeks, respectively (Table 3 and 4).

These data indicate a considerable degree of precision and reproducibility for the methods both during one analytical run and between different runs.

By comparison of coefficient of variation (CV) for the two methods, HPLC appeared somewhat more precise than HPTLC, particularly at low analyte concentrations.

\subsubsection{Accuracy}

The interference of excipients in the pharmaceutical formulations was studied in detail by the HPLC and HPTLC methods. For this reason, the standard addition method was applied to the pharmaceutical formulation containing these compounds. In application of standard addition method to the pharmaceutical formulation, the mean percentage recoveries and their standard deviations for the proposed methods were calculated (Table 5). According to the obtained results, satisfactory precision and accuracy were observed for these methods. Consequently, the excipients in pharmaceutical formulation do not interfere in the analysis of these compounds in the pharmaceutical formulation.

\subsubsection{System suitability}

Resolution (Rs) is a measure of the degree of separation between adjacent peaks. A value of 1.5 for resolution implies a complete separation of the two compounds [37]. Additionally, British Pharmacopoeia specifies that the symmetry factor of a principal peak must be between 0.8 and 1.5 [37]. Resolutions and other system suitability parameters were calculated for MIC, NYS, HCA and NS. Their values were found to be acceptable (Table 6).

\subsubsection{Ruggedness and robustness tests}

As recommended in the ICH guidelines and the Dutch Pharmacists guidelines, a robustness assessment was performed during the development of the analytical procedure [38]. 
Table 3. Intra-day and inter-day precision of MIC and NYS standard solutions by HPLC method.

\begin{tabular}{|c|c|c|c|c|c|}
\hline \multirow[t]{2}{*}{ Compound } & \multirow[t]{2}{*}{ Theoretical concentrations $(\mu \mathrm{g} / \mathrm{mL})$} & \multicolumn{2}{|c|}{ Intra-day Precision } & \multicolumn{2}{|c|}{ Inter-day Precision } \\
\hline & & Recovery\% $\%$ S.D & CV\% & Recovery\% $\%$ S.D & CV\% \\
\hline \multirow{4}{*}{ MIC } & 4 & $99.02 \pm 0.63$ & 0.64 & $98.88 \pm 0.90$ & 0.91 \\
\hline & 12 & $98.02 \pm 0.73$ & 0.74 & $98.86 \pm 0.89$ & 0.90 \\
\hline & 20 & $99.72 \pm 0.56$ & 0.56 & $99.26 \pm 0.67$ & 0.68 \\
\hline & 20 & $99.04 \pm 0.96$ & 0.97 & $100.04 \pm 1.17$ & 1.17 \\
\hline \multirow[t]{2}{*}{ NYS } & 60 & $98.96 \pm 0.83$ & 0.84 & $99.06 \pm 0.93$ & 0.94 \\
\hline & 100 & $99.80 \pm 0.69$ & 0.69 & $99.50 \pm 1.03$ & 1.04 \\
\hline \multirow{3}{*}{ HCA } & 4 & $99.87 \pm 0.69$ & 0.69 & $99.73 \pm 1.98$ & 1.98 \\
\hline & 12 & $99.82 \pm 0.49$ & 0.49 & $100.12 \pm 0.84$ & 0.84 \\
\hline & 20 & $100.04 \pm 0.39$ & 0.39 & $100.09 \pm 0.73$ & 0.73 \\
\hline \multirow{3}{*}{ NS } & 20 & $99.14 \pm 0.68$ & 0.69 & $99.92 \pm 2.01$ & 2.01 \\
\hline & 60 & $99.93 \pm 0.56$ & 0.56 & $99.85 \pm 0.89$ & 0.89 \\
\hline & 100 & $100.02 \pm 0.41$ & 0.41 & $100.07 \pm 0.75$ & 0.75 \\
\hline
\end{tabular}

Table 4. Intra-day and inter-day precision of MIC and NYS standard solutions by HPTLC method.

\begin{tabular}{|c|c|c|c|c|c|}
\hline \multirow[t]{2}{*}{ Compound } & \multirow[t]{2}{*}{ Theoretical concentrations $(\mu \mathrm{g} / \mathrm{band})$} & \multicolumn{2}{|c|}{ Intra-day Precision } & \multicolumn{2}{|c|}{ Inter-day Precision } \\
\hline & & Recovery\% \pm S.D & CV\% & Recovery\% $\%$ S.D & CV\% \\
\hline \multirow{3}{*}{ MIC } & 4 & $97.40 \pm 0.73$ & 0.75 & $97.89 \pm 0.94$ & 0.96 \\
\hline & 12 & $97.02 \pm 0.83$ & 0.86 & $98.06 \pm 0.92$ & 0.94 \\
\hline & 20 & $98.62 \pm 0.66$ & 0.67 & $98.26 \pm 0.77$ & 0.78 \\
\hline & 20 & $98.10 \pm 0.96$ & 0.98 & $99.34 \pm 1.32$ & 1.33 \\
\hline \multirow[t]{3}{*}{ NYS } & 60 & $98.06 \pm 0.93$ & 0.95 & $98.30 \pm 0.99$ & 1.01 \\
\hline & 100 & $98.08 \pm 0.89$ & 0.91 & $98.70 \pm 1.13$ & 1.15 \\
\hline & 4 & $98.07 \pm 0.79$ & 0.81 & $98.93 \pm 2.01$ & 2.05 \\
\hline \multirow[t]{3}{*}{ HCA } & 12 & $98.04 \pm 0.69$ & 0.70 & $99.02 \pm 0.99$ & 1.00 \\
\hline & 20 & $99.04 \pm 0.49$ & 0.50 & $99.39 \pm 0.85$ & 0.86 \\
\hline & 20 & $98.14 \pm 0.78$ & 0.80 & $98.72 \pm 2.01$ & 2.04 \\
\hline \multirow[t]{2}{*}{ NS } & 60 & $97.93 \pm 0.66$ & 0.67 & $98.95 \pm 0.99$ & 1.00 \\
\hline & 100 & $99.02 \pm 0.61$ & 0.62 & $99.47 \pm 0.88$ & 0.89 \\
\hline
\end{tabular}

Table 5. Determination of MIC, NYS, HCA and NS in Monicure NH® vaginal suppositories ${ }^{a}$ using the proposed HPLC and HPTLC methods.

\begin{tabular}{|c|c|c|c|c|}
\hline & MIC & NYS & HCA & NS \\
\hline \multicolumn{5}{|l|}{$\overline{\text { HPLC }}$} \\
\hline Mean recovery $(\%) \pm S D$ & $100.61 \pm 1.03$ & $99.57 \pm 1.01$ & $99.91 \pm 0.66$ & $100.26 \pm 0.82$ \\
\hline 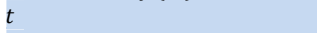 & $(2.18)^{b}$ & & & \\
\hline$f$ & $(4.28)^{\mathrm{b}}$ & & & \\
\hline \multicolumn{5}{|l|}{ HPTLC } \\
\hline Mean recovery $(\%) \pm S D$ & $100.14 \pm 1.04$ & $99.96 \pm 0.78$ & $99.89 \pm 0.74$ & $99.89 \pm 1.05$ \\
\hline$t$ & 0.56 & 0.32 & 0.31 & 0.34 \\
\hline$f$ & 1.11 & 1.01 & 1.69 & 1.05 \\
\hline \multicolumn{5}{|l|}{ Standard addition technique $\mathrm{c}$} \\
\hline HPLC [Mean recovery $(\%) \pm S D]$ & $101.15 \pm 1.09$ & $99.95 \pm 0.85$ & $100.17 \pm 0.33$ & $99.55 \pm 0.93$ \\
\hline HPTLC [Mean recovery $(\%) \pm S D]$ & $101.10 \pm 0.88$ & $100.10 \pm 1.04$ & $100.18 \pm 0.94$ & $99.92 \pm 0.91$ \\
\hline
\end{tabular}

a Monicure NH® vaginal suppositories labeled to contain $100 \mathrm{mg} \mathrm{MIC,} 20.6 \mathrm{mg}$ NYS, $5 \mathrm{mg}$ HCA and $50 \mathrm{mg}$ NS per suppository.

b Theoretical values for $t$ and $F$ at $p=0.05$.

c For standard addition of $50 \%$ of the nominal content.

Table 6. Parameters required for system suitability testing of the proposed HPLC method.

\begin{tabular}{|c|c|c|c|c|c|}
\hline Parameters & NYS & HCA & MIC & NSC-PIC & NSB-PIC \\
\hline Resolution (Rs) & 3.83 & - & 14.20 & 1.63 & - \\
\hline Selectivity $(\alpha)$ & 1.63 & - & 2.21 & 1.18 & - \\
\hline Symmetry factor $(T)$ & 1.01 & 1.04 & 1.10 & 1.09 & 1.00 \\
\hline Capacity factor (k') & 0.90 & 1.47 & 3.25 & 1.20 & 1.42 \\
\hline Number of theoretical plates $(\mathrm{N})$ & 757 & 4432 & 2501 & 1716 & 5791 \\
\hline HETP (cm/plate) & 0.03 & 0.005 & 0.01 & 0.014 & 0.004 \\
\hline
\end{tabular}

The ruggedness [39] of the two methods was assessed by comparison of the intra-day and inter-day assay results for MIC, NYS, HCA and NS that were performed by two analysts. The CV\% values for intra-day and inter-day assays of the four analytes in the Monicure $\mathrm{NH}$ vaginal suppositories performed in the same laboratory by two analysts did not exceed 3.8\%, indicating the ruggedness of the two methods. In addition, the robustness of the method was investigated under a variety of conditions, including changes of the flow rate, $\mathrm{PH}$ and mobile phase composition [40].

\subsection{Analysis of MIC and NYS in Monicure NH vaginal suppositories}

The two methods were applied to the determination of MIC, NYS, HCA and NS in commercial Monicure NH vaginal suppositories. Recoveries were calculated using external regression equations. No interfering peaks were observed from any of the excipients. The assay results revealed satisfactory accuracy and precision, as indicated by the recovery and SD values (Table 5).

Recovery data resulting from the proposed HPLC and HPTLC methods were statistically compared with those of the reported HPLC methods: [14,17,30,39] for MIC NYS, HCA and NS, respectively, using one way ANOVA. It was found that the calculated $\mathrm{F}$ values did not exceed the critical value of the $\mathrm{F}$ ratio at $\alpha=0.05$, indicating no significant differences between the proposed and reported methods (Table 7)

\subsection{Methods comparison}

The two proposed analytical methods were compared in term of sensitivity, precision and accuracy to further assess their applicability in the analysis of real samples. 
Table 7. ANOVA test for statistical comparison of the recovery data results obtained by the proposed HPLC and HPTLC methods and reported methodsa.

\begin{tabular}{|c|c|c|c|c|c|c|}
\hline Compound & Source of variation & Sum of squares (SS) & Degree of freedom (df) & Mean sum of squares (MS) & $F$-ratio b & $P$-value \\
\hline \multirow[t]{3}{*}{$\overline{\mathrm{MIC}}$} & Between & 1.86 & 2 & 0.93 & \multirow[t]{3}{*}{0.83} & \multirow[t]{3}{*}{0.46} \\
\hline & Within & 13.48 & 12 & 1.12 & & \\
\hline & Total & 15.34 & 14 & - & & \\
\hline \multirow[t]{3}{*}{$\overline{N Y S}$} & Between & 3.60 & 2 & 1.80 & \multirow[t]{3}{*}{1.67} & \multirow[t]{3}{*}{0.23} \\
\hline & Within & 12.91 & 12 & 1.08 & & \\
\hline & Total & 16.51 & 14 & - & & \\
\hline \multirow[t]{3}{*}{ HCA } & Between & 0.06 & 2 & 0.03 & \multirow[t]{3}{*}{0.24} & \multirow[t]{3}{*}{0.79} \\
\hline & Within & 1.42 & 12 & 0.12 & & \\
\hline & Total & 1.48 & 14 & - & & \\
\hline \multirow[t]{3}{*}{ NS } & Between & 0.06 & 2 & 0.03 & \multirow[t]{3}{*}{0.19} & \multirow[t]{3}{*}{0.83} \\
\hline & Within & 1.71 & 12 & 0.14 & & \\
\hline & Total & 1.76 & 14 & - & & \\
\hline
\end{tabular}

a Reported methods are $[14,17,30,39]$ for MIC NYS, HCA and NS, respectively.

b The critical value of $F$-ratio is 3.89 at $\alpha=0.05$.

As shown in Table 1 and 2, compared to HPTLC method, The HPLC-DAD method was found to be more sensitive (linearity range, LOD) in quantitating the cited drugs. The quantitation limits of the cited drugs using the HPLC are lower than those obtained using the HPTLC method.

The overall precision (CV\%) (Table 3 and 4) and accuracy (recovery \%) (Table 5) of the HPLC-DAD method are superior to that of the HPTLC method particularly at low analyte concentrations. However the HPTLC method is advantageous with respect to simplicity and duration

\section{Conclusion}

In conclusion, our study suggests that HPTLC is an acceptable technique only for samples with high concentrations of MIC, NYS, HCA and NS. However, we should consider that HPTLC is cheaper and faster than HPLC, since on a single plate at least 10-15 samples can be analysed in 2-3 $\mathrm{h}$.

\section{Acknowledgement}

The authors would like to acknowledge financial assistance from Faculty of Pharmacy, Suez Canal University, Ismailia, Egypt.

\section{References}

[1]. Reynolds, J. E. F. (ed). Martindale: The Extra Pharmacopoeia, 29th ed., Pharmaceutical Press, London, 1989, pp. 430, 666.

[2]. Hardman, J. G.; Limbird, L. E. (eds). Goodman \& Gilman's: The Pharmacological Basis of Therapeutics, $9^{\text {th }}$ ed., McGraw- Hill, New York, 1996.

[3]. USP DI, 24th edition, Drug Information for the Health Care Professional, 2004.

[4]. Sweetman, S. C. (ed). Martindale: The complete drug reference, $35^{\text {th }}$ ed., Pharmaceutical Press, London, 2002, p. 392.

[5]. Lemus, G. J. M.; Perez, A. J. Chromatographia 2002, 55, 749-753.

[6]. Waksman, S. A. Neomycin. Nature, Formation, Isolation, and Practical Application, Rutgers University Press, New Brunswick, NJ, 1953.

[7]. Waksman, S. A.; Lechevalier, H. A. Guide to the Classification and Identification of the Actinomycetes and their Antibiotics, The Williams \& Wilkins Co., Baltimore, MD, 1953.

[8]. Waksman, S. A. Neomycin. Its Nature and Practical Application, The Williams \& Wilkins Co., Baltimore, MD, 1958.

[9]. Rinehart, K. L. The neomycins and related antibiotics, in: Chemistry of Microbial Products E. R. Squibb Lectures on Chemistry of Microbial Products, Institute of Microbiology, John Wiley \& Sons, Inc. , New York, NY, 1964

[10]. Kobylinska, M.; Kobylinska, K.; Sobik, B. J. Chromatogr B: Biomed. Appl. 1996, 685, 191-195.

[11]. Goger, N. G.; Gokcen, L. Anal. Lett. 1999, 32, 2595-2602.

[12]. Wrobel, K.; Wrobel, K.; de la Garza Rodriguez, I. M.; Lopezde-Alba, P. L.; Lopez Martinez, L. J. Pharm. Biomed. Anal. 1999, 20, 99-105.

[13]. Khashaba, P. Y.; El-Shabouri, S. R.; Emara, K. M.; Mohamed, A. M. J. Pharm. Biomed. Anal. , 2003, 22, 363-376.

[14]. Akay, C.; Ozkan, S. A.; Senturk, Z.; Cevheroglu, S. Il Farmaco 2003, 57, 953-957.

[15]. Lupan, L.; Bandula, R.; Vasilescu, M.; Bercu, C. Fresenius J. Anal. Chem. 1996, 355, 409-411.
[16]. Botsoglou, N. A.; Fletouris, D. J. J. Agr. Food Chem. 1996, 44, 1271 1274

[17]. Groll, A. H.; Mickiene, D.; Werner, K.; Pistelli, S. C.; Walsh, T. J. J. Chrom. $B$ 1999, 735, 51-57.

[18]. Yeo, S. K.; Lee, H. K.; Li, S. F. Y. J. Chrom. A 1991, 585, 133-137.

[19]. Raith, K.; Althoff, E.; Banse, J.; Neidhardt, H.; Neubert, R. H. H. Electrophoresis 1998, 19, 2907-2911.

[20]. Heneedak, H.; Salama, I.; Mostafa, S.; El-Sadek, M. J. Chrom. Sci. 2012 50, 855-861.

[21]. Bonazzi, D.; Andrisano, V.; Gatt, R.; Cavrini, V. J. Pharm. Biomed. Anal. 1995, 13, 1321-1329.

[22]. Amin, A. S. Anal. Lett. 1996, 29, 1527-1537.

[23]. Medenica, M.; Ivanovic, D.; Markovic, S.; Malenovic, A.; Jancic, B. Pharmind. 2004, 66, 330-333.

[24]. Gagliardi, L.; De Orsi, D.; Giudice, M. R. D.; Gatta, F.; Porra, R.; Chimenti, P.; Tonelli, D. Anal. Chim. Acta. 2002, 457, 187-198.

[25]. Chauhan, V.; Conway, B. Chromatographia 2005, 61, 555-559.

[26]. Hajkova, R.; Solich, P.; Dvocak, J.; Cicha, J. J. Pharm. Biomed. Anal. 2003, 32, 921-927.

[27]. Jancic-stojanovic, B.; Malenovic, A. J. AOAC Int. 2010, 93, 102-107.

[28]. Hay, M.; Mormed, P. J. Chrom. B. 1997, 702, 33-39.

[29]. Grippa, E.; Santini, L.; Castellano, G.; Gatto, M. T.; Leone, M. G.; Saso, L. J. Chrom. B 2000, 738, 17-25.

[30]. Majid, O.; Akhlaghi, F.; Lee, T.; Holt, D. W.; Trull, A. Ther. Drug Monit. 2001, 23, 163-168.

[31]. Shaikh, B.; Jackson, J.; Guyer, G.; Ravis, W. R. J. Chrom. B: Biomed. Appl. 1991, 571, 189-198.

[32]. Medina, M. B.; Unruh, J. J. J. Chrom. B 1995, 663, 127-135.

[33]. Oertel, R.; Renner, U.; Kirch, W. J. Pharm. Biomed. Anal. 2004, 35, 633638.

[34]. Oertel, R.; Neumeister, V.; Kirch, W. J. Chrom. A 2004, 1058, 197-201.

[35]. Byoung-Hyoun, K.; Suk Chin, L.; Hye Jin, L.; Jong Hoa, O. Biomed. Chrom. 2003, 17, 396- 403.

[36]. International Conference on Harmonisation of Technical Requirements for Registration of Pharmaceuticals for Human Use, ICH Harmonised Tripartite Guideline-Validation of Analytical Procedures: Text and Methodology Q2(R1), Current Step 4 version, London, 2005.

[37]. The British Pharmacopoeia, Her Majesty's Stationery Office. London UK, 2008, pp 404-405, 485-486, 1080-1081, 1382, 2519-2520, 25592560, 2592-2593, 2766-2767, 2861.

[38]. Zeaiter, M.; Roger, J. M.; Maurel, V. B.; Rutledge, D. N. Trends. Anal. Chem. 2004, 23, 157-170.

[39]. Mulholland, M. Trends Anal. Chem. 1988, 7, 383-389.

[40]. Heyden, Y. V.; Nijhuis, A.; Verbeke, J. S.; Vandeginste, B. G. M.; Massaret, D. L. J. Pharm. Biomed. Anal. 2001, 24, 723-753. 